\title{
PEMANFAATAN LIMBAH KOTORAN HEWAN PADA CAMPURAN BETON
}

\author{
Nurul Rochmah \\ Dosen Prodi Teknik Sipil, Fak. Teknik, UNTAG Surabaya \\ e-mail: nurul-rochmah@untag-sby.ac.id
}

\begin{abstract}
ABSTRAK
Pembangunan bidang konstruksi belakangan ini mengalami perkembangan, termasuk salah satu material suatu konstruksi yaitu beton. Banyak sekali penelitian-penelitian yang dilakukan dalam pengembangan teknologi beton. Hal ini disebabkan beton salah satu material dalam suatu pembangunan yang banyak dipakai. Dipihak lain di beberapa wilayah Indonesia banyak sekali limbah-limbah kotoran hewan, msekipun bukan limbah pabrik, limbah kotoran hewan ini sangat mengganggu pencemaran udara serta bisa menjadi pusat penyebaran penyakit. Dikarenakan di daerah-daerah tertentu Indonesia banyak kotoran sapi maka dipenelitian ini akan menggunakan kotoran sapi sebagai bahan tambah campuran beton. Alasan digunakan kotoran sapi ini, dikarenakan kotoran sapi mengandung unsur silika yang yaitu 9,6\% per kilogramnya, dimana silika ini kandungan utama penyusun semen, sehingga diharapkan dengan penambahan limbah kotoran hewan ini bisa meningkatkan fungsi semen dalam campuran beton. Dalam penelitian ini mencari nilai slump dan resapan pada proporsi bahan tambah abu kotoran sapi 0\%, 5\%, 10\%, 15\%. Hasil penelitian ini diperoleh nilai minimum slump $5,5 \mathrm{~cm}$ dan resapan 2,1\% pada proporsi bahan tambah abu kotoran sapi $10 \%$
\end{abstract}

\section{Kata kunci : Bahan tambah, Kotoran Sapi, Beton}

\begin{abstract}
The construction sector has recently experienced developments, including one of the construction materials, namely concrete. Lots of research has been carried out in the development of concrete technology. Concrete is one of the materials in a construction that is widely used. On the other hand, in several parts of Indonesia there is a lot of animal waste, even though it is not factory waste, this animal waste is very disturbing to air pollution and become the center of the spread of disease. Because in certain areas of Indonesia there is a lot of cow dung, this study used it as an added material to the concrete mixture. The reason for using it because it contains silica,
\end{abstract}


namely $79 \%$ over a kilogram, where this silica is the main constituent of cement, so it is hoped that the addition of animal waste can improve the function of cement in the concrete. In this study, looking for the value of slump and infiltration in the proportion of materials added to cow dung ash 0\%, 5\%, 10\%, 15\%. The results of this study obtained a minimum slump value of $5.5 \mathrm{~cm}$ and $2.1 \%$ infiltration in the proportion of $10 \%$ added material ashes of cow dung.

Key words: added material, cow dung, concrete

\section{PENDAHULUAN}

Perkembangan dalam pembangunan konstruksi belakangan ini terjadi di banyak negara, termasuk negara berkembang Indonesia. Hal ini karena kebutuhan masyarakat akan fasilitas struktur yang semakin meningkat, antaralain : pembangunan tower, gedung bertingkat, jembatan yang terbuat dari beton. Beton merupakan campuran dari semen Portland ataupun semen hidrolis yang lain, aggregate kasar, aggregat halus, air dan tanpa atau dengan bahan tambah (SNI-03-2847-2013). Aggregat yaitu material berupa kerikil, pasir serta batu pecah dimana dipakai secara bersama menggunakan pengikat sehingga akan terbentuk beton semen adukan atau hidrolik.

Perkembangan masa sekarang masalah lingkungan tidak hanya diperoleh dari pabrik-pabrik tekstil dan bahan kimia, tapi juga suatu peternakan juga mengakibatkan masalah lingkungan. Permasalahan yang komplek ditimbulkan oleh limbah kotoran adalah mencemari lingkungan, menjadi sumber penyakit, pemandangan menjadi terganggu serta bau yang tidak sedap. Indonesia yang terdiri dari beragam daerah dan tradisi, di salah satu suku yang bernama sasak yang berada di pulau Lombok, mempunyai rumah adat yang menggunakan kotoran sapi. Masyarakat disana menggunakan kotoran sapi untuk membersihkan dinding dan juga mengepel. Kotoran sapi dipergunakan oleh suku sasak untuk pengganti semen dalam membuat tangga dan dinding. Masyarakat tersebut menggunakan tanah liat, sekam padi dan campuran kotoran sapi untuk membuat lantai. Penelitian mengenai kotoran sapi menunjukkan kandungan silika limbah tersebut sebesar 9,6\% per kilogramnya (Astuti, 2016). Dengan kandungan silika sebesar itu, maka limbah ini mempunyai sifat yang sama dengan semen, yaitu pozzolanic.

PAWON: Jurnal Arsitektur, Nomor 02 Volume V, Juli-Desember Tahun 2021, ISSN 2597-7636 


\section{TINJAUAN PUSTAKA}

Beberapa penelitian terdahulu yang menjadi referensi penelitian ini antaralain: Pengaruh Penambahan Kotoran Sapi sebagai Substitusi Semen terhadap Kuat Tekan Beton dimana penelitian ini menjadikan abu kotoran sapi sebagai substitusi dari semen dengan variasi persentase mulai dari $0 \%$, kemudian, $5 \%$, lalu $7 \%$ dan terakhir $10 \%$, benda uji yang dipakai silinder $15 \times 30$ dan total berjumlah 36 benda uji, pengetest an dilakukan pada hari ke 7, lalu 14 kemudian 28. Hasil yang optimal kuat tekan diperoleh 18,3 KN pada hari ke 28. (Fawaid dan Qudsyi Ainul,2019).Pemanfaatan Kotoran Sapi Untuk Material Konsruksi Dalam Upaya Pemecahan Masalah Sosial Serta Peningkatan Taraf Ekonomi Masyarakat dimana penelitian ini tentang penggunaan kotoran sapi yang dicampur dengan tanah liat serta sekam padi dalam pemecahan permaslahan sosial untuk pembuatan batu bata. Dimana dari penelitian tersebut juga dijelaskan bisa meningkatkan penghasilan masyarakat sekitar karena dalam pembuatan batu bata tersebut membutuhkan harga rendah dengan kualitas lebih baik. (Muhammad Dwi N dan Muhammad Dzikri R,2014)

\subsection{Semen sebagai material penyusun Beton}

Semen yaitu suatu bahan yang akan mengeras ketika beraksi dengan air dan disebut juga bahan pengikat. Bahan utama semen adalah batu kapur, tanah liat dan bahan alumina/silica serta oksida besi.

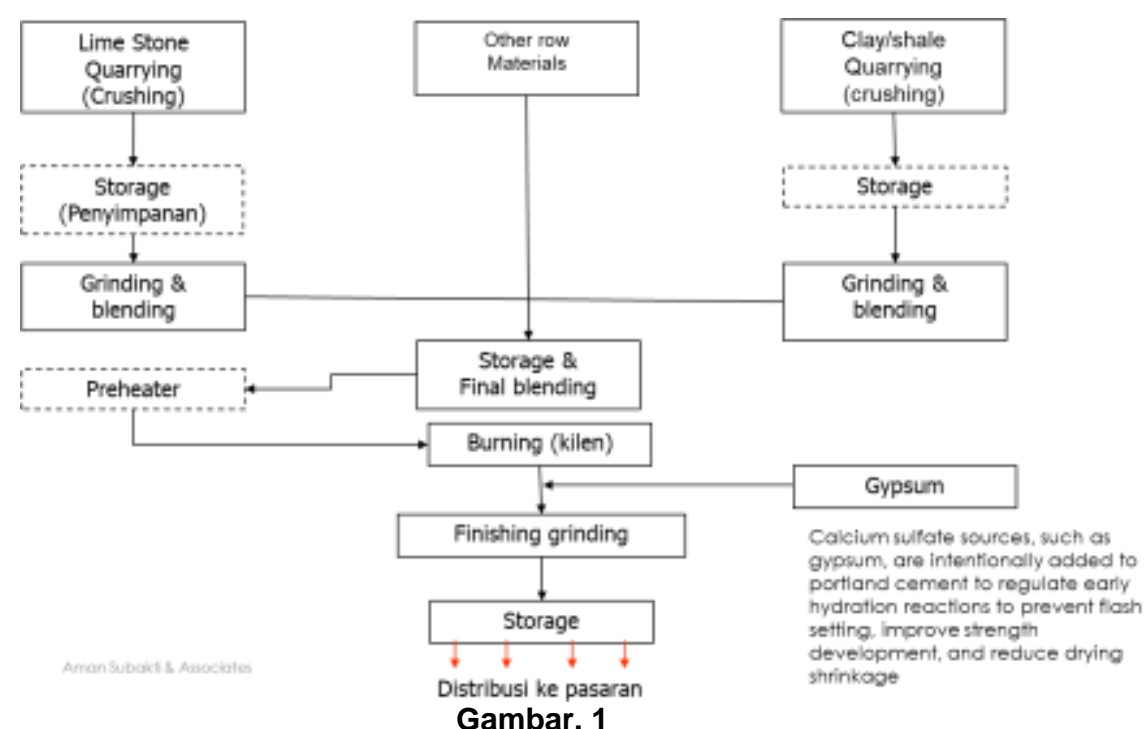

Gambar Bagan proses pembuatan semen

(Sumber : Subakti, 2010) 


\subsection{Aggregat sebagai material penyusun Beton}

Aggregat berfungsi sebagai material pengisi yang berupa butiran mineral. Aggregat ini terdiri dari dua yaitu aggregat halus dan aggregate kasar. Dimana aggregat halus itu butiran yang lolos saringan $4,78 \mathrm{~mm}$, sedangkan aggregate kasar itu butiran yang tertahan saringan $4,78 \mathrm{~mm}$.

Tabel 1

Gradasi Saringan Agregat Halus (SNI 03-2834-2000 dan ASTM C-33)

\begin{tabular}{|c|c|c|c|c|c|}
\hline \multirow{2}{*}{$\begin{array}{c}\text { Diameter } \\
\text { Saringan } \\
(\mathrm{mm})\end{array}$} & \multicolumn{5}{|c|}{$\begin{array}{c}\text { Persen Lolos } \\
(\%)\end{array}$} \\
\cline { 2 - 6 } & $\begin{array}{c}\text { Pasir Kasar } \\
\text { (Gradasi } \\
\text { No.1) }\end{array}$ & $\begin{array}{c}\text { Sasir } \\
\text { Sedang } \\
\text { (Gradasi } \\
\text { No.2) }\end{array}$ & $\begin{array}{c}\text { Pasir Agak } \\
\text { Halus } \\
\text { (Gradasi } \\
\text { No.3) }\end{array}$ & $\begin{array}{c}\text { Pasir } \\
\text { Halus } \\
\text { (Gradasi } \\
\text { No.4) }\end{array}$ & $\begin{array}{c}\text { ASTM C- } \\
\text { aggreg } \\
\text { ate }\end{array}$ \\
\hline 9,5 & $100-100$ & $100-100$ & $100-100$ & $100-100$ & 100 \\
\hline 4,75 & $90-100$ & $90-100$ & $90-100$ & $95-100$ & $95-100$ \\
\hline 2,36 & $60-95$ & $75-100$ & $85-100$ & $95-100$ & $80-100$ \\
\hline 1,18 & $30-70$ & $55-90$ & $75-100$ & $90-100$ & $50-58$ \\
\hline 0,6 & $15-34$ & $35-59$ & $60-79$ & $80-100$ & $25-60$ \\
\hline 0,3 & $5-20$ & $8-30$ & $12-40$ & $15-50$ & $5-30$ \\
\hline 0,15 & $0-10$ & $0-10$ & $0-10$ & $0-15$ & $0-10$ \\
\hline
\end{tabular}

(Sumber : Buku Petunjuk Praktikum Beton UNTAG, 2018)

Tabel 2

Gradasi Saringan Ideal Agregat Kasar

\begin{tabular}{|c|c|c|}
\hline $\begin{array}{c}\text { Diameter Saringan } \\
(\mathrm{mm})\end{array}$ & $\begin{array}{c}\text { Persen Lolos } \\
(\%)\end{array}$ & $\begin{array}{c}\text { Gradasi Ideal } \\
(\%)\end{array}$ \\
\hline 25 & 100 & 100 \\
\hline 19 & $90-100$ & 97,5 \\
\hline 12,5 & - & - \\
\hline 9,5 & $20-55$ & 37,5 \\
\hline 4,75 & $0-10$ & 5 \\
\hline 2,36 & $0-5$ & 2,5 \\
\hline
\end{tabular}


( Sumber : ASTM C 33 "Standard Spesification for Concrete Aggregates", 2003)

\subsection{Air sebagai material penyusun Beton}

Air dalam material penyusun beton berfungsi sebagai bahan pencampur aggregat dan semen. Dimana air yang digunakan sebagai bahan pencampur di beton mempunyai beberapa persyaratan antaralain: tidak ada kandungan minyak, lumpur, bahan lainnya yang tersuspensi lebih besar dari $2 \mathrm{gr} / \mathrm{l}$, tidak mengandung garam, asam serta zat organic lain lebih besar dari $15 \mathrm{gr} / \mathrm{l}$ dan air yang diragukan harus di cek dengan cara kimia dan setelah itu melakukan evaluasi dari hasil pengecekan tersebut.

\subsection{Abu Kotoran Sapi}

Dari hasil beberapa pengamatan suatu penelitian bahwa rata-rata satu ekor sapi mengeluarkan kotoran sebesar 25 kg/ekor/hari (Wahyuni,2015). Dampak lingkungan dari adanya pelakuk peternakan bisa berupa pencemaran terhadap tanah, air dan udara yang berpotensi mengganggu kesehatan manusia dan ternak itu sendiri.

Kotoran Sapi mempunyai kandungan kalium, nitrogen, kalsium dan fosfor. Dimana kotoran sapi yang dijemur di bawah sinar matahari dan setelah itu dilakukan pembakaran akan menghasilkan Abu kotoran sapi.

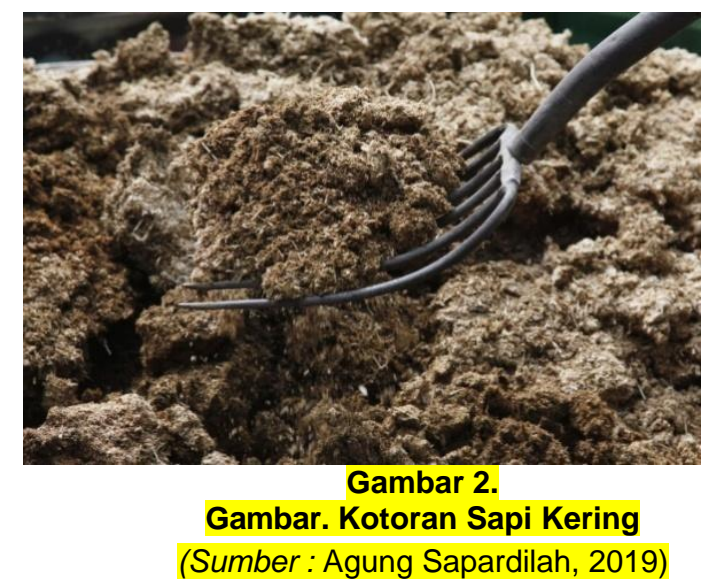

PAWON: Jurnal Arsitektur, Nomor 02 Volume V, Juli-Desember Tahun 2021, ISSN 2597-7636 


\subsection{Resapan Beton}

Uji resapan beton adalah cara yang penting untuk menggambarkan dan mengetahui kualitas dan kekuatan beton yang diperoleh. Beton yang punya kualitas bagus baik mempunyai daya serap air kecil yang mana jumlah pori pada permukaan rapat dan sedikit.

Penyerapan air pada beton Menurut SNI 03-2914-1990, dapat dihitung

$$
\text { Penyerapan air }=\frac{m j-m k}{m k} x 100 \%
$$

Dimana :

$\mathrm{mj}=$ Massa sampel jenuh (gram)

$\mathrm{mk}=$ Massa sampel kering (gram)

\subsection{Slump Test}

Uji Slump merupakan suatu uji untuk mengetahui tingkat workability(tidak dapat dikerjakan atau dapat dikerjakan).

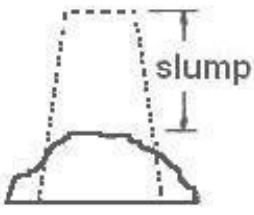

Collapse

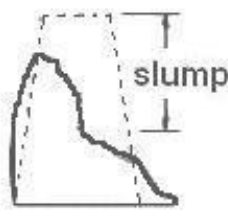

Shear

Types of slump

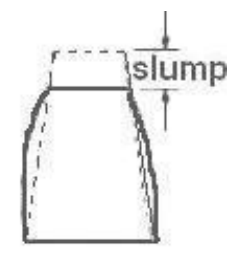

True slump

Gambar 3.

Gambar Jenis-Jenis Slump Test

(Sumber : Subakti, 2010)

- Gambar 1 : runtuh dimana keadaan terlalu banyak air

- Gambar 2 : Shear terjadi karena belum tercampur dengan rata adukan tersebut

- Gambar 3 : True merupakan slum yang ideal dan benar 

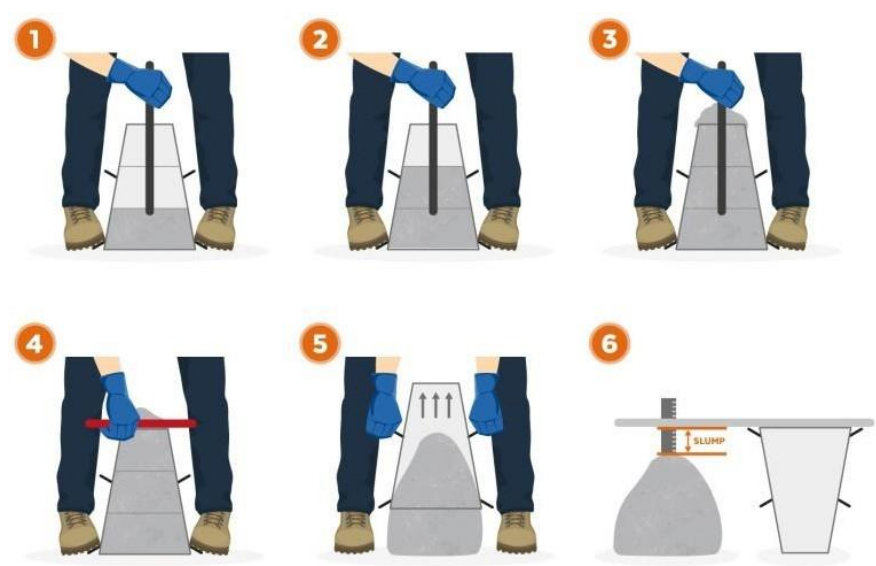

Gambar 4.

Gambar Tahapan Slump Test

(Sumber : Amirin, 2018)

Tabel 3

Standar Nilai Slum

\begin{tabular}{|c|l|c|c|}
\hline No & \multicolumn{1}{|c|}{ Elemen Struktur } & $\begin{array}{c}\text { Slump } \\
\text { maks }\end{array}$ & Slump min \\
\hline 1. & Plat, pondasi telapak bertulang & $12,5 \mathrm{~cm}$ & $5,0 \mathrm{~cm}$ \\
\hline 2. & $\begin{array}{l}\text { Pondasi telapak tidak bertulang, kaison } \\
\text { dan konstruksi dibawah tanah }\end{array}$ & $9,0 \mathrm{~cm}$ & $2,5 \mathrm{~cm}$ \\
\hline 3. & Plat (lantai), kolom dan dinding & $15,0 \mathrm{~cm}$ & $7,5 \mathrm{~cm}$ \\
\hline 4. & Jalan beton bertulang & $7,5 \mathrm{~cm}$ & $5,0 \mathrm{~cm}$ \\
\hline 5. & Pembetonan massal & $7,5 \mathrm{~cm}$ & $2,5 \mathrm{~cm}$ \\
\hline
\end{tabular}

(Sumber : Lauw Tjin Nji, 2011)

Berdasarkan pendahuluan tentang perkembangan beton yang pesat sehingga ada banyak penelitian tentang beton dan dipihak lain adanya permasalahan limbah kotoran hewan secara umum, khususnya kotoran sapi yang mengandung bahan tinggi silika dimana kandungan silika juga adalah zat penyusun semen sehingga berdasar hal tersebut bisa ditarik kesimpulan sementara, kotoran sapi ini mempunyai sifat yang sama dengan semen, serta penelitian terdahulu tentang kotoran sapi sebagai substitusi semen. Berdasarkan permasalahan tersebut, untuk meminimalisir limbah kotoran sapi, penulis mencoba untuk membuat campuran beton dengan bahan tambah dari limbah kotoran sapi dengan proporsi bahan tambah tersebut antaralain $0 \%, 5 \%, 10 \%, 15 \%$, untuk mengetahui nilai slump dan resapan..

PAWON: Jurnal Arsitektur, Nomor 02 Volume V, Juli-Desember Tahun 2021, ISSN 2597-7636 


\section{METODE PENELITIAN}

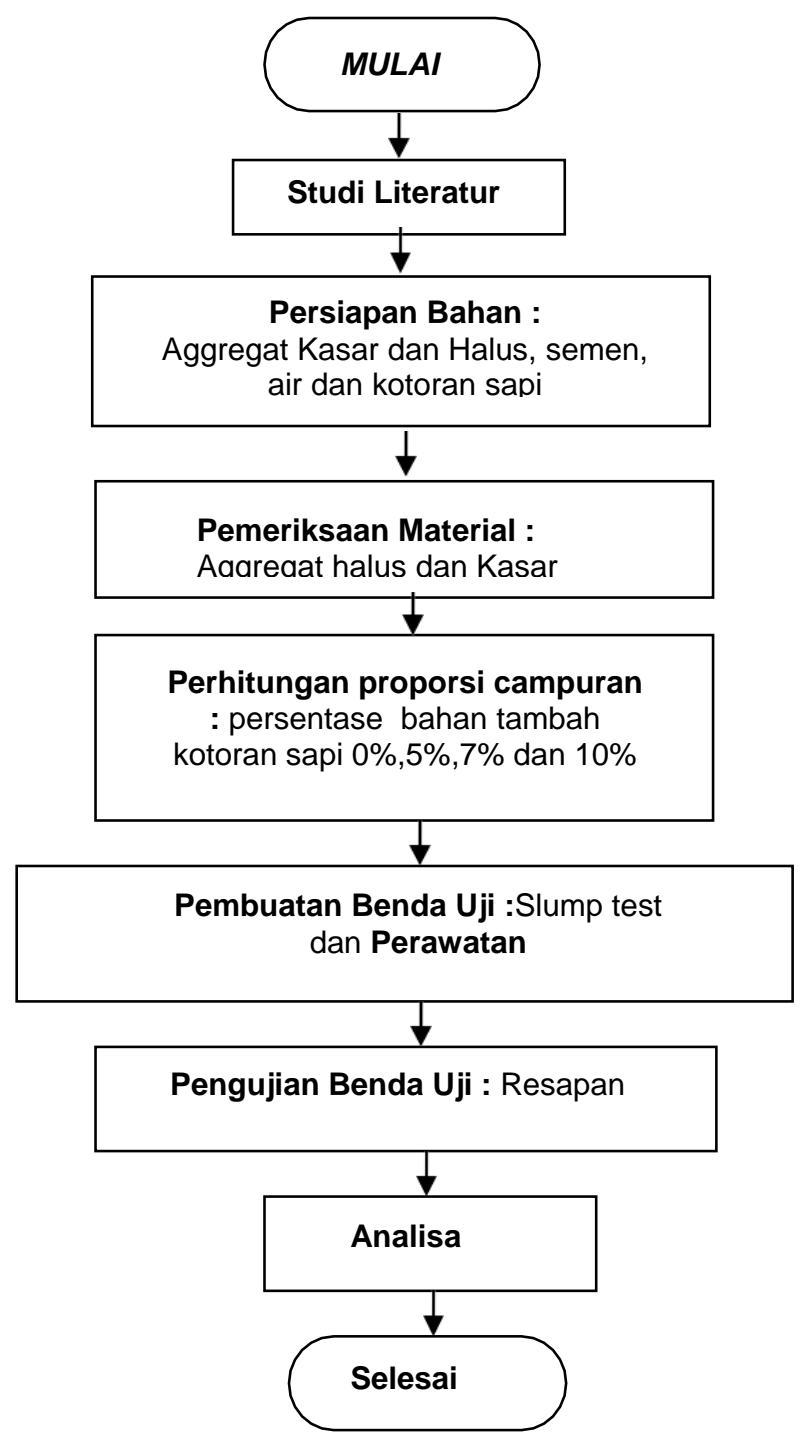

Gambar 5.

Gambar Diagram Alir Penelitian

PAWON: Jurnal Arsitektur, Nomor 02 Volume V, Juli-Desember Tahun 2021, ISSN 2597-7636 


\subsection{Keterangan Diagram Alir}

Penelitian ini dimulai dengan persiapan bahan pengisi beton, bahanbahan tersebut antaralain: aggregat halus, aggregate kasar semen, air dan bahan tambah, dalam hal ini memakai bahan tamba kotoran sapi.

Setelah semua bahan disiapkan, maka dilakukan pengujian material, yaitu material aggregate kasar, di tes keausan, gradasi aggregate, berat jenis, kadar air dan penyerapan nya. Begitu pula dengan aggregate halus dilakukan pengujian material aggregate halus, gradasi aggregate halus, kadar air, kelembapan serta penyerapan.

Kemudian dilanjutkan perhitungan perbandingan proporsi bahan penyusun beton dengan metode DOE. Dalam perhitungan proporsi ini hasil pemeriksaan aggregate halus dan aggregate kasar dimasukkan sebagai salah satu data perhitungan. Dari perhitungan ini diperoleh proporsi aggregate kasar, aggregate halus, semen, air dan bahan tambah untuk tiap benda uji. Dalam penelitian ini menggunakan pencetak benda uji berbentuk silinder.

Dari hasil proporsi perhitungan dengan metode DOE, maka bahanbahan di campur dengan mesin pencampur. Sebelum dimasukkan ke pencetak benda uji, beton segar di tes slump terlebih dahulu. Setelah diperoleh nilai slump, maka campuran beton segar di masukkan pencetak berbentuk silinder. Kemudian dilakukan perawatan/curing dengan merendam benda uji di dalam air. Setelah itu tes uji resapan.

Tabel 4

Pembuatan Benda Uji

\begin{tabular}{|c|c|c|}
\hline $\begin{array}{l}\text { Proporsi bahan } \\
\text { tambah kotoran } \\
\text { sapi (\%) }\end{array}$ & Resapan & Total benda uji \\
\cline { 2 - 2 } & hari ke 28 & \\
\hline 0 & 3 benda uji & \multirow{2}{*}{ 12 buah } \\
\hline 5 & 3 benda uji & \\
\hline 10 & 3 benda uji & \\
\hline 15 & 3 benda uji & \\
\hline
\end{tabular}

Sumber : Hasil Penelitian Penulis, 2020 


\section{HASIL DAN PEMBAHASAN}

\subsection{Slump Test}

Tabel 5

slump test untuk beton resapan

\begin{tabular}{|c|c|c|c|}
\hline $\begin{array}{l}\text { Abu Kotoran } \\
\text { Sapi } \\
(\%)\end{array}$ & $\begin{array}{c}\text { Tinggi Awal } \\
(\mathrm{mm})\end{array}$ & $\begin{array}{c}\text { Tinggi Akhir } \\
(\mathrm{mm})\end{array}$ & $\begin{array}{c}\text { Nilai Slump } \\
(\mathrm{mm})\end{array}$ \\
\hline 0 & 300 & 200 & 100 \\
\hline 5 & 300 & 250 & 50 \\
\hline 10 & 300 & 245 & 55 \\
\hline 15 & 300 & 240 & 60 \\
\hline
\end{tabular}

Sumber : Hasil Penelitian Penulis, 2020

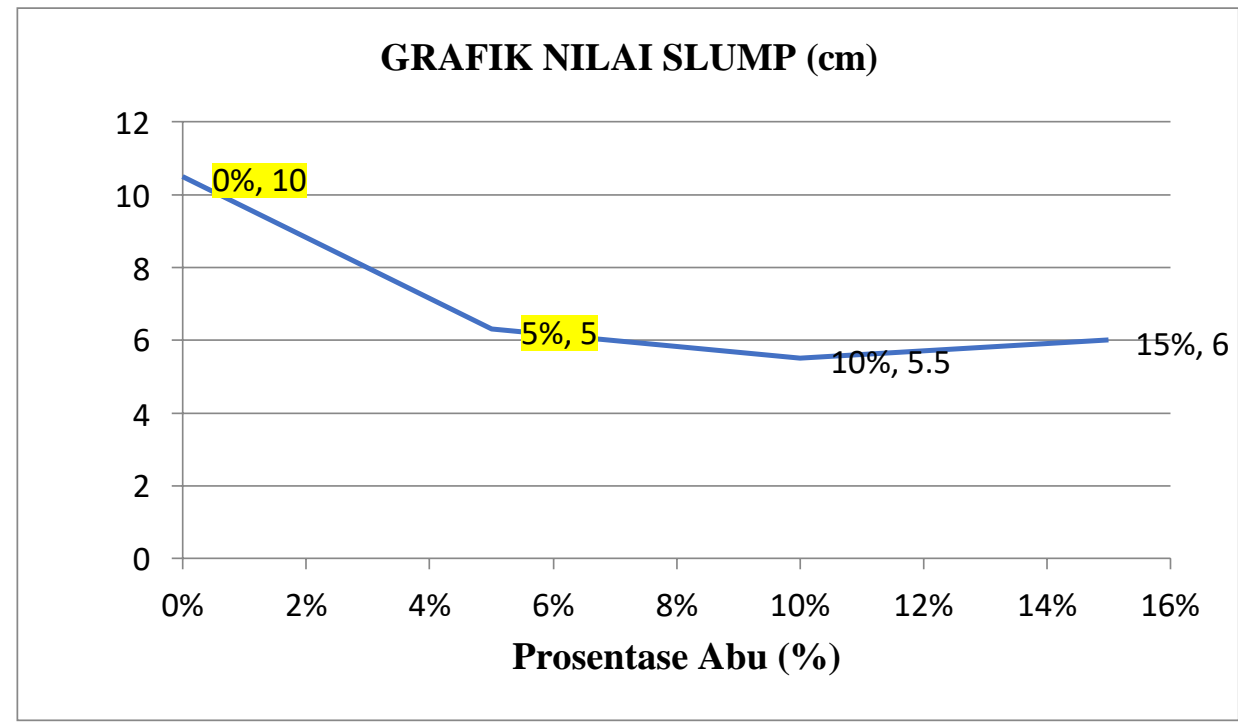

Gambar 6.

Gambar Grafik Nilai Slump

Dari hasil uji slump diatas di tunjukkan berupa tabel dan grafik, dimana perbedaan 2 bentuk tersebut yang tabel dalam satuan $\mathrm{mm}$, tetapi yang grafik dalam satuan $\mathrm{cm}$. Terlihat hasil tes yang memungkinkan menghasilkan kuat tekan maksimal yaitu pada hasil slump yang minimal yang terjadi pada persentase $10 \%$ dimana nilai slump adalah $5,5 \mathrm{~cm}$ atau 55 $\mathrm{mm}$. 


\subsection{Resapan Beton}

Tabel 6

Resapan untuk beton

\begin{tabular}{|c|c|c|c|c|c|}
\hline \multicolumn{2}{|c|}{$\begin{array}{c}\text { Nama } \\
\text { sample }\end{array}$} & $\begin{array}{c}\text { W Beton } \\
\text { dalam SSD } \\
(\mathrm{g})\end{array}$ & $\begin{array}{l}\text { W Beton } \\
\text { setelah di } \\
\text { Oven } \\
(\mathrm{g})\end{array}$ & $\begin{array}{l}\text { Nilai } \\
\qquad \begin{array}{l}\text { Resapan } \\
\text { (per 100) }\end{array}\end{array}$ & Rerata \\
\hline \multirow{3}{*}{$0 \%$} & a. & 12800 & 12300 & $406 / 100$ & \multirow{3}{*}{$3,7 \%$} \\
\hline & b. & 13000 & 12500 & $400 / 100$ & \\
\hline & c. & 12800 & 12400 & $320 / 100$ & \\
\hline \multirow{3}{*}{$5 \%$} & a. & 12700 & 12400 & $240 / 100$ & \multirow{3}{*}{$2,4 \%$} \\
\hline & b. & 12700 & 12400 & $240 / 100$ & \\
\hline & c. & 12800 & 12500 & $240 / 100$ & \\
\hline \multirow{3}{*}{$10 \%$} & a. & 12800 & 12500 & $240 / 100$ & \multirow{3}{*}{$2,1 \%$} \\
\hline & b. & 12700 & 12500 & $160 / 100$ & \\
\hline & c. & 12800 & 12500 & $240 / 100$ & \\
\hline \multirow{3}{*}{$15 \%$} & a. & 12800 & 12400 & $320 / 100$ & \multirow{3}{*}{$3,4 \%$} \\
\hline & b. & 12800 & 12300 & $406 / 100$ & \\
\hline & c. & 12900 & 12500 & $320 / 100$ & \\
\hline
\end{tabular}

\section{GRAFIK NILAI RESAPAN}

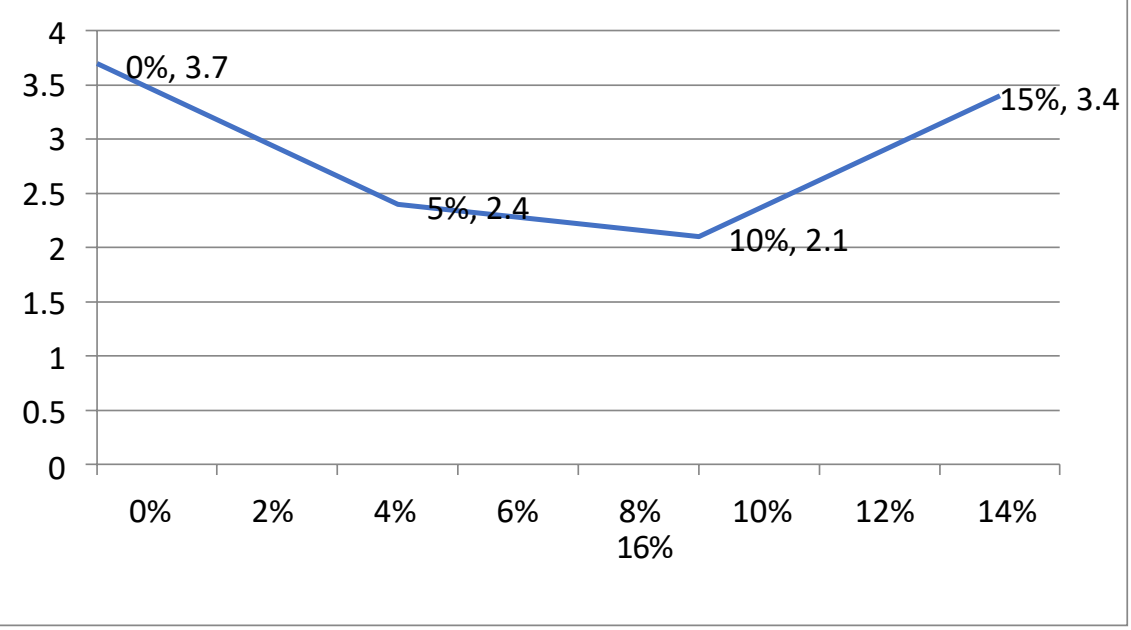

Gambar 7

Gambar Grafik Nilai Resapan

PAWON: Jurnal Arsitektur, Nomor 02 Volume V, Juli-Desember Tahun 2021, ISSN 2597-7636 
Dari hasil uji resapan diatas terlihat hasil tes yang mempunyai hasil resapan optimal ketika mempunyai nilai resapan paling rendah yaitu yang terjadi pada persentase $10 \%$.

\section{KESIMPULAN}

Berdasarkan hasil dan pembahasan diatas diperoleh hasil uji slump terlihat hasil tes yang memungkinkan menghasilkan kuat tekan maksimal yaitu pada hasil slump yang minimal yang terjadi pada persentase $10 \%$ dan uji resapan diatas terlihat hasil tes yang mempunyai hasil resapan optimal ketika mempunyai nilai resapan paling rendah yaitu yang terjadi pada persentase $10 \%$. Jadi proporsi optimal campuran beton pada penelitian ini menggunakan bahan tambah $10 \%$ kotoran sapi.

\section{DAFTAR PUSTAKA}

SNI 03-2847-2013, Persyaratan Beton Struktural Untuk Bangunan Gedung, Badan Standardisasi Nasional, Jakarta

Fawaid \& Qudsyi Ainul.(2020). Pengaruh Penambahan Kotoran Sapi sebagai Substitusi Semen terhadap Kuat Tekan Beton. Bogor: library of IPB University.

Muhammad Dwi N \& Muhammad Dzikri R.(2014). Pemanfaatan Kotoran Sapi Untuk Material Konsruksi Dalam Upaya Pemecahan Masalah Sosial Serta Peningkatan Taraf Ekonomi Masyarakat.Jurnal Sosioteknologi Volume 13, Nomor 2.

Subakti, A . M. Irmawan, B. Piscesa (2010) . Teknologi Beton dalam Praktek, Surabaya. ITS Press

Trimurtiningrum, Retno.(2018). Material Penyusun Beton dan Persyaratannya (Materi Kuliah Teknologi Beton), Surabaya. Untag Surabaya

ASTM Standart C33. (2003). Standard Spesification for Concrete Aggregates, (ASTM C 33-03). Whest Conshohocken, PA, USA:ASTM International.

Wahyuni, Sri (2015) Panduan Praktis Biogas. Jakarta : Penebar Swadaya. Astuti, Sri.(2016). Uji Kualitas Batu Bata Dari Limbah Kotoran Sapi. Universitas Islam Negeri Alauddin Makassar. 